\title{
Ameliyat öncesi planlama, önemi
}

\section{Preoperative planning and its significance}

\author{
Vahit Emre Özden, Burak Beksaç, İ. Remzi Tözün
}

Acıbadem Üniversitesi Ortopedi ve Travmatoloji Bölümü, İstanbul

\begin{abstract}
Kalça eklem artroplastisinde elde edilen sonucun başarı derecesi, hastanın durumuna ve uygulanan ameliyata bağlı olduğu kadar, ameliyat öncesi etkili olabilecek tüm faktörlerin iyi değerlendirilmesine ve ameliyatın iyi planlanmış olmasına da bağlıdır. Hastadan alınacak hikaye ve sonrasında klinik muayene doğrultusunda yapılacak tetkikler planlamanın temelini oluşturur. Özellikle enfeksiyon gibi ameliyata engel olabilecek veya cerrahi yöntemi değiştirecek patolojilerin tespiti şarttır. Uygun standartlarda çekilmiş olan radyografiler ise planlamada vazgeçilmezdir. Grafiler üzerinden yapılan şablonlama ile kullanılacak komponentlerin yeri ve özellikleri belirlenir. Asetabuler komponent, pelviste belirli radyografik referans noktaları yardımı ile hareket merkezine uygun yerleştirilmelidir. Femur boynu kesi seviyesi için bacak boyu uzunluk farkı dikkate alınır ve asetabulum hareket merkezine göre ayarlanarak uygun seviyeden yapılır. Şablonlamada femur anatomisine uygun femoral komponent denenir ve ameliyatta belirlenen büyüklüğe ve ofsete sahip komponentler hazır bulundurulur. Planlama cerrahın ameliyatta işini kolaylaştırır ve karşılacağı olası zorluklara karşı hazır olmasını sağlar. Ancak, implant tipi ve boyutları ile ilgili kesin karar ameliyat sırasında ortaya çıkan tabloya bağlı olarak verilir.
\end{abstract}

Anahtar sözcükler: ameliyat öncesi dönem; vücut şablonlama; total kalça replasmanı; bacak uzunluğu eşitsizliği
The success of the hip arthroplasty depends upon good planning and detailed analysis of the parameters which may affect the surgical outcome in advance, as well as the specific condition of the patient and a successful surgical procedure. Preoperative planning, taking into consideration the characteristics of the case is the starting point, which is as important as the execution of the surgery. Medical tests performed in the light of a carefully obtained medical history and a thorough physical examination form the basis of planning. It is crucial that conditions such as infection, which will contradict surgical treatment is not missed. Appropriate radiographs are vital for planning and should be taken in conformity with the standards. Preoperative templating performed on the radiographs determine the placement and the dimensions of the components. Acetabular component must be placed according to the center of motion, using landmarks such as the teardrop figure, ilioischial line, acetabular borders in the pelvis radiograph. Appropriately sized femoral component is determined with templates and the femoral neck osteotomy is performed in order to adjust leg length with reference to the new acetabular center, created with the acetabular implant. The predicted components (size and offset) are made available during the surgery. Planning facilitates the surgeon's guesswork and prepares him/her for possible intraoperative problems. However, the final decision on the implant type and size is made during the surgery with respect to patient's anatomy and bone quality.

Key words: preoperative period; body patterning; total hip replacement; leg length inequality
K alça eklem artroplastisinde amaç ağrısız ve hareketi tam olan bir eklem elde etmektir. Artroplasti uygulamasında bu amaç doğrultusunda mükemmel sonuç; uygulanacak yönteme, kullanılacak cerrahi malzemeye, fizyoterapiye ve hastanın uyumuna bağlıdır. Ameliyat öncesi tüm bu faktörlerin değerlendirilmesi ve planlama, uygulama aşaması kadar önemlidir.

\section{HIKAYE}

Hastanın hikayesi ve mevcut sağlık durumu, uygulanacak implantın yapısı, tespit yöntemi ve cerrahi yaklaşım üzerinde belirleyici rol oynar. Bu nedenle; yaş, cinsiyet, ameliyat öncesi tanı, aktivite seviyesi ve mental durumu, diğer eklemlerin durumu veya yardımcı destek alet kullanımına engel durumun varlığı, medikal

- İletişim adresi: Op. Dr. Vahit Emre Özden, Acıbadem Maslak Hastanesi, Büyükdere Cad No: 40, 34457, Maslak, Sarıyer, İstanbul Tel: 0212 - 3044373 e-posta: vahitemre@gmail.com

- Geliș tarihi: 27 Mart 2013 Kabul tarihi: 11 Temmuz 2013 
problemler ve beklentiler; ve nihayet, beklenen yaşam süresi değerlendirilmelidir.

Planlama aşamasında şablonlama önemli bir yer tutar. Fakat, planlama sadece hasta grafileri üzerinde şablonlar ile yapılan ölçümlerden ibaret değildir. Hastanın hikayesi ve klinik muayenesi sonucu elde edilen bilgiler, direk grafilerin genel değerlendirilmesi, yapılacak müdahaleye eksiksiz hazırlanmada ve uygulama sırasında yardımcı olur.

Geçmişte alçı veya breys ile tedavi hikayesi olan kimsede kalça problemi asetabuler displazi veya Perthes gibi rahatsızlıkların sekeli olabilir. Alt ekstremitede torsiyonel deformitelerin daha sık görüldügü bu gibi durumlarda muayene ve değerlendirmenin bu doğrultuda yapılması gerekir. Özellikle geçmişte ekleme ait akıntı veya enfeksiyon hikayesi, yapılacak olan planlamada ve cerrahinin uygulaması aşamasında belirleyici rol oynar. Hastanın aktif enfeksiyonu artroplasti için kontrendikasyon oluştururken, uzak geçmişteki enfeksiyon sorun oluşturmayabilir. ${ }^{[1,2]}$ Vücutta herhangi bir odakta sessiz seyreden bir enfeksiyonun varlığı, eritrosit sedimantasyon hızı (ESR) ve C-reaktif protein (CRP) değerleri ile araştırılmalıdır. En azından rutin olarak alınacak idrar ve burun sürüntüsü kültür örnekleri ile olası sık görülen enfeksiyon odakları kontrol edilmelidir. Ayrıca gerekirse, eklemi ilgilendiren aktif enfeksiyon şüphesi durumunda, ameliyat öncesi eklem aspirasyonu yapılabilir. Ameliyat sırasında da anormal görünümdeki dokulardan patolojik ve mikrobiyolojik örnek alınması gerekebileceği düşünülerek hazırlık yapılmalıdır.

Hikayede geçirilmiş ameliyatlar ayrıntılı olarak sorgulanmalıdır. Aynı bölgeden ameliyat hikayesinin olması uygulanacak cerrahi yaklaşımda belirleyici olabilir. Eski insizyon skarı ile yeni planlanan insizyon arasında kalan alanda gelişebilecek dolaşım problemini engellemek için parallel insizyon tercih edilmelidir. Eğer ilk insizyonu çaprazlayacaksak, $90^{\circ}$ 'de yaklaşmak oluşabilecek problemleri en aza indirir. ${ }^{[3]}$ Ayrıca, uygulanmış bir implant varsa, cinsi ve özellikleri tespit edilmeli ve çıkarılması için gereken malzemeler önceden tedarik edilmelidir.

Kalça protezi yapılacak olan hasta yaş grubunda damar problemleri mevcut olabilir. Önceden damar rekonstrüksiyonu hikayesi mevcut ise özellikle femoral kanal hazırlanmasında verilecek pozisyona dikkat edilmesi gerekir. Verilen pozisyonlarda femoral damarda tromboz gelişebilir. ${ }^{[4]}$ Gerekirse damar tamiri yapılmış alana zarar vermemek için trokanterik osteotomi uygulanabilir ${ }^{[5]}$ veya anterior veya anterolateral yaklaşım denenebilir.

\section{FiZiK MUAYENE}

Ameliyat öncesi muayene öncelikle gözlem ile başlar. Kalça çevresi yumuşak doku ve cildin genel durumu gözlenir. Önceki ameliyatlara ait olan insizyon izleri belirlenir. Hastanın yürüyüşü ve genel duruşu gözlemlenir. Kalça ve komşu eklemlerin hareket aralıkları, fikse veya fonksiyonel deformiteler belirlenir. Örneğin, aşırı lordozu olan hastaya asetabuler komponent standart öne ve yana açılım ile uygulanırsa, lordozun düzelmesi ile örtünmede yetersizlik ve instabilite gelişebilir. ${ }^{[6]}$ Bundan dolayı lumbosakral eklemdeki deformasyonun sabit olup olmadığı tespit edilmelidir.

Bacak boyu eşitsizliği olan hastada skolyoz, poliomyelit, gelişimsel kalça displazisi, dejeneratif lomber veya torakal disk problemleri, spinal füzyon hikayesi araştırılmalı ve planlamada göz önünde bulundurulmalıdır. Alt ekstremiteler arasındaki uzunluk farkı tespit edilmelidir. "Görünen uzunluk farkı" umbilikustan medial malleollere kadar ölçülen mesafe ile değerlendirilir. Fakat yumuşak doku kontraktürü ve pelvik asimetriyi değerlendirmez. Fizik muayenede ekstremitedeki abduksiyon, adduksiyon veya fleksiyon kontraktürleri değerlendirilmeli uzunluk farkına olan etkileri belirlenmelidir. Fleksiyon kontraktürü kısalığın daha fazla hissedilmesine neden olurken, abduksiyon kontraktürü ekstremitenin uzun hissedilmesine neden olur. Kısa bacak altına yerleştirilen bloklar ile pelvis dengelenir ve "fonksiyonel uzunluk farkı" belirlenir. "Gerçek uzunluk farkı" ise her iki taraf spina iliaka anterior superior ile medial malleol arasındaki mesafelerin farkı ile ölçülür. Bu en güvenilir klinik yöntemdir fakat bu yöntem ekstremite ve pelvisin pozisyonuna göre kontraktür durumlarında farklılık gösterir. ${ }^{[7]}$ Fonksiyonel ve gerçek uzunluklar arasında farklılık pelvik asimetrinin değerlendirilmesini gerektirir. Oturarak ve ayakta hemipelvis seviyelerine bakılır. Suprapelvik asimetri oturur pozisyonda devam eder, bunun tersi infrapelvik anomalilerde ise düzelir. ${ }^{[8]}$ Özellikle diz kontraktürü gibi deformitelerin bulunduğu ekstremitede, uzunluk farkının tespitinde en kesin tanı yöntemi femur ve tibia uzunluklarının ayrı ayrı ölçülebileceği bilgisayarlı tomografi (BT) tetkikidir. ${ }^{[9]}$

Kalça eklemi kontraktürlerinin tespiti, ameliyat öncesi planlamada, özellikle cerrahi yaklaşım açısından önem taşır. Abduksiyon kısıtlılığı olan ve adduktor kontraktürü bulunan olguda lateral dekübit pozisyonu verilmeden önce supin pozisyonda adduktor gevşetme yapılması gerekebilir. Devamlı tekerlekli sandalyede oturan, fleksiyon ve adduksiyon kontraktürü bulunan kimselerde ameliyat sonrası kontraktür gelişme olasılığı yüksektir. Benzer durum, serebrovasküler olay geçirmiş veya serebral palsi gibi spastisitesi olan hastalar için de geçerlidir. ${ }^{[10]}$ Bu tip hastalarda posterior 
yaklaşım dislokasyon açısından daha riskli olacağından anterior veya anterolateral yaklaşım tercih edilmelidir. Heterotopik ossifikasyon nedeni ile ankiloze olmuş kalçada trokanterik osteotomiden uzak durmak ve ameliyat sonrasında radyoterapiyi planlamak gerekir. Anterolateral yaklaşım ve çimentosuz femoral komponent kullanımının heterotopik ossifikasyon olasılığını arttıracağını gösteren çalışmalar da mevcuttur. [11] Hastanın yürüyüşüündeki aksamanın nedeni bacak boyu eşitsizliği ve eklem sertliği dışında, kas zaafiyeti de olabilir. Trendelenburg test pozitifliği veya gluteus medius aksaması abduktor kas zaafiyetini gösterir. Bu durumda, seçilecek olan komponent ile femoral ofsetin arttırılması veya trokanter majörün laterale kaydırılması abduktor kas gücünü destekler. Abduktor kolun tamamen eksikliğinde ise tripolar veya kısıtlıyıcı tip içliklerin kullanılması, olası çıkık riskini azaltmak için önerilir. ${ }^{[12,13]}$

Fizik muayene sırasında sadece ameliyat olacak ekstremite değil diğer ekstremite ve eklemlerin durumu ameliyat planlamasında ve özellikle öncelik sıralamasında rol oynar. Örneğin, kalça artroplastisi, normal yürüyüşü bozan ayak deformitesi varlığında, ayak tabanı ile basış sağlayacak ayak ameliyatı sonrası düşünülmelidir. ${ }^{[14]}$ Aynı anda hem kalça hem de diz artrozu olan hastada diz artroplastisi uygulaması sonrası rehabilitasyon sırasında gelişebilecek zorluklarından dolayı, bu uygulamanın kalça artroplastisini takiben yapılması daha iyi olur. ${ }^{[6]}$

\section{RADYOGRAFIK DEĞERLENDIRME VE ŞABLONLAMA}

Ameliyat öncesinde çekilecek direkt radyografiler; simfizis pubise odaklı tam pelvis anteroposterior (AP) grafisi, etkilenen kalça merkezine odaklı kalça tam AP ve lateral grafilerini içerir. Pelvis grafisi ile karşı kalça eklemi ve kalça eklemi kaynaklı uzunluk farkı değerlendirilmesi yapılır. Kalça grafilerinde, özellikle femur ve asetabulumun yapısı incelenir. AP grafi hasta supin yatar pozisyonda ve mümkünse bacak $15^{\circ}$ iç rotasyonda çekilir. Böylelikle $15^{\circ}$ anteversiyon boyun açısı bulunan femurun tam AP görüntüsü ve gerçek ofseti elde edilir. Eğer patolojiden dolayı kalçaya iç rotasyon verilemiyorsa, değerlendirme için diğer kalça kullanılır. ${ }^{[15]}$ Her iki kalçanın etkilendiği durumda, proksimal femur geometrisi hasta yüzüstü pozisyonda diğer kalçanın yerden etkilenen kalçadaki rotasyon miktarı kadar kaldırılması ile elde edilebilir. ${ }^{[14]}$ Lateral grafi, femoral kanalın anatomisini ve kanalın piriform fossa ile ilişkisini belirlemek için kullanılır. ${ }^{[16]}$

Alt ekstremitede kırık veya osteotomi hikayesi varlığında femurun tamamını ve tüm alt ekstremitenin dizilimini gösteren ortoröntgenografi istenmelidir. Asetabuler travma hikayesi varlığında ise Judet grafileri ve gerekli görülürse BT ile değerlendirme, olası asetabuler yetersizliklere karşı hazırıklı olmayı sağlar.

Asetabulum ve femurun şekli ve trabeküler yapısı, ameliyat öncesi hem tanı hem de kullanılacak implantın seçimi açısından önemlidir. Post-travmatik deformiteler, Paget hastalığı ve fibröz displazi gibi patolojiler femurun proksimal kısmında değişikliklere neden olurlar. Femur proksimal geometrisi ve kemik kalitesine göre düzenlenmiş sınıflamalar seçilecek olan implantın çimentolu veya çimentosuz uygulanması konusunda yol göstericidir. Özellikle, proksimal femur kalkar-kanal genişliği oranı ile hesaplanan Dorr indeksi günümüzde en sık kullanılan yöntemdir. ${ }^{[17]}$

Çekilmiş grafilerde yapılacak ölçümler için filmlerdeki büyütme oranının bilinmesi gerekir. Normalde çekim masasından $102 \mathrm{~cm}$ uzaklıkta çekilmiş olan grafide büyütme oranı \%10 olacaktır. Ancak hasta kilolu ise kemik kaset mesafesi artacağından, büyütme \%25'e kadar artabilir. ${ }^{[18]}$

Grafilerin genel olarak değerlendirilmesi sırasında sakrum ve koksiksin, pubik simfizis hizasında olmaması veya obturator deliklerin asimetrik duruşu, pelviste rotasyonu gösterir. ${ }^{[19]}$ Kalça fleksiyon kontraktürü nedeni ile gelişen hiperlordoz pelvisin tam AP görüntüsünü engelleyebilir ve ölçüm için gerekli noktaların tespitinde sıkıntıya neden olur. Kalçada sabit fleksiyon kontraktüründe femur üst ucunu tam değerlendirmek için kontraktür kadar gövde kaldırılarak, oturur durumda, uyluk röntgen masasına paralel bir şekilde tam temas eder duruma getirilmelidir. Pelvisi değerlendirmek için ise, hasta supin pozisyonda, uyluk fleksiyon kontraktürü kadar fleksiyona getirilip pelvis AP görüntüsü alınmalıdır.

Şablonlama, grafide uygun referans noktaların tespiti ile başlar. Gözyaşı figürleri kalça eklem hareket noktalarına yakın olmaları itibari ile en güvenilir anatomik belirleyici noktalardır. ${ }^{[20]}$ Gözyaşı figürlerinin tabanından çekilen horizontal çizgi şablonlamanın ilk aşamasıdır. Alternatif referans noktaları olarak sakroiliak eklemlerin distal ucu veya iskial tuberkulumların distal kısımları seçilebilir. Ayrıca ameliyat sırasında görülebilecek bazı noktaların işaretlenmesi faydalı olacaktır. Gözyaşı figürü, ilioiskial çizgi ve asetabulumun superolaterali asetabuler taraf için işaretlenir (Şekil 1, 3).

Asetabulumun düzgün yerleştirilmesi eklem stabilitesi açısından vazgeçilmez bir koşuldur. Asetabuler komponent şablonu, ilioiskial çizgiye yakın ve lateralden yeterli örtünme sağlanarak, abduksiyon açısı $40^{\circ} \pm 10^{\circ}$ ve asetabulumdan $2 \mathrm{~mm}$ subkondral kemik alınacak şekilde yerleştirilmelidir (Şekil 1). Çimentolu 


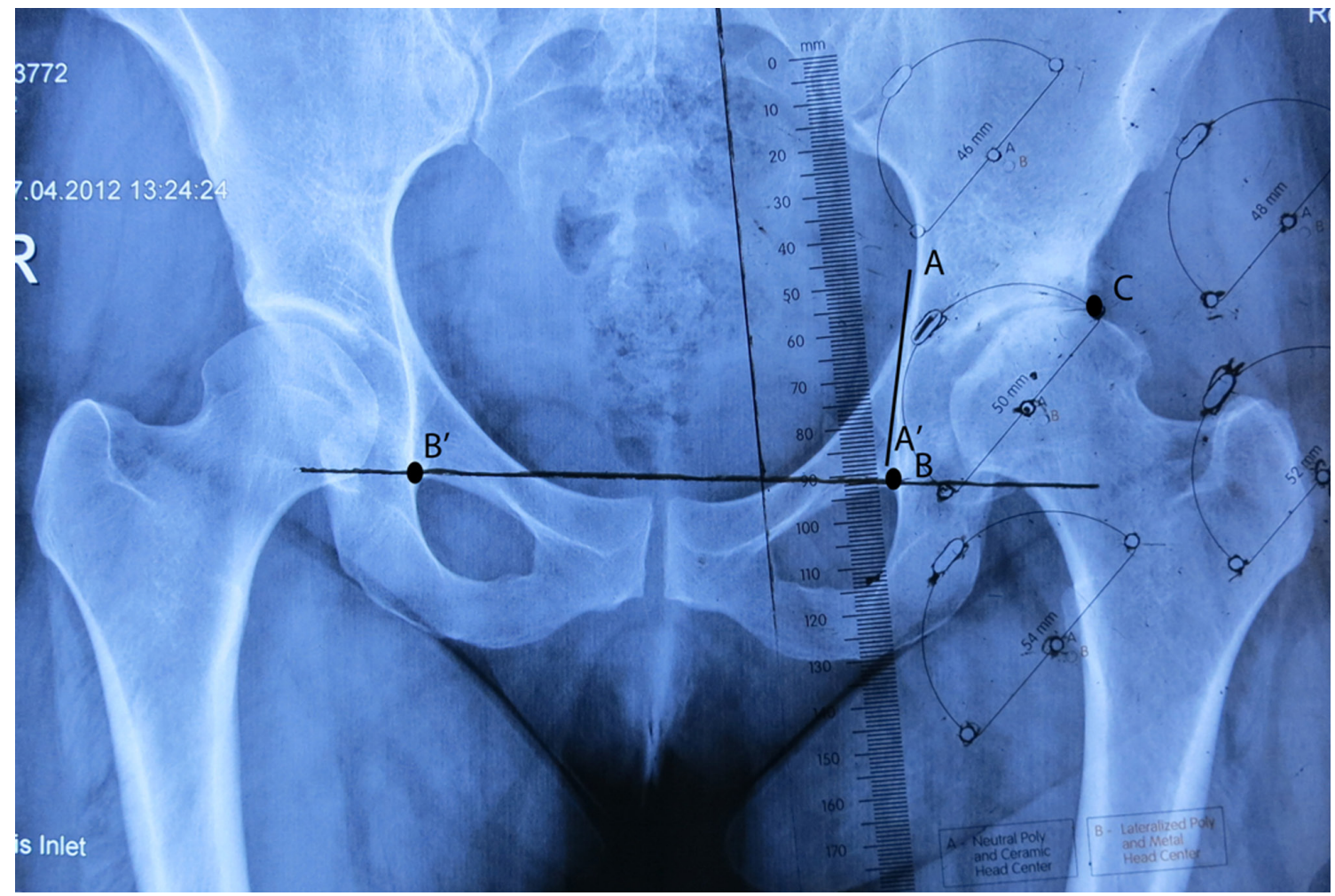

Şekil 1. Asetabuler şablonlama. İlioiskial çizgi (A-A'), Gözyaşı figürleri alt sınırlarından çizilen referans çizgi (B-B'), Asetabulumun superolateral kenarı (C).

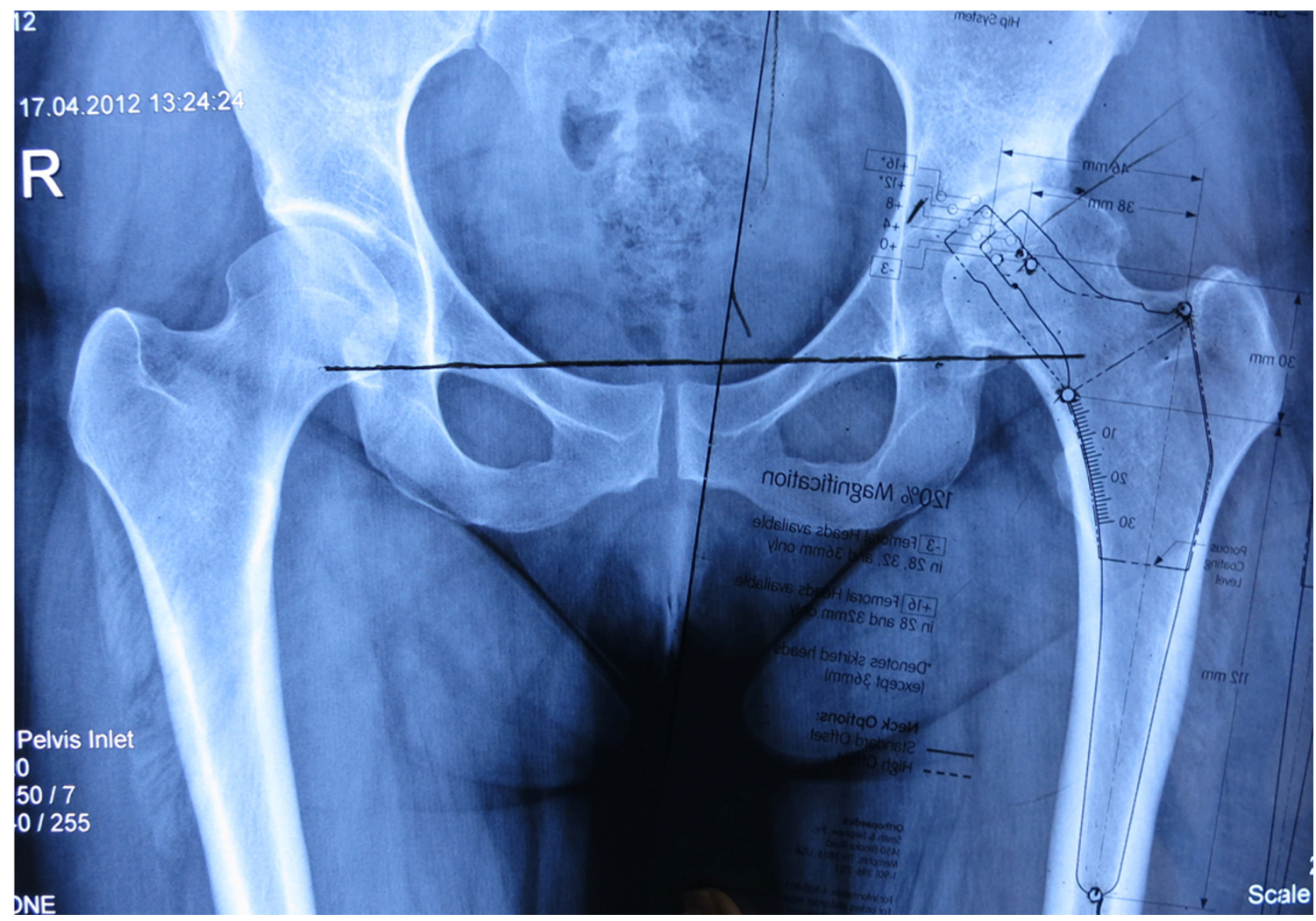

Şekil 2. Femoral şablonlama. Proksimal kaplı çimentosuz femoral komponent şablonu ile uygulama. 


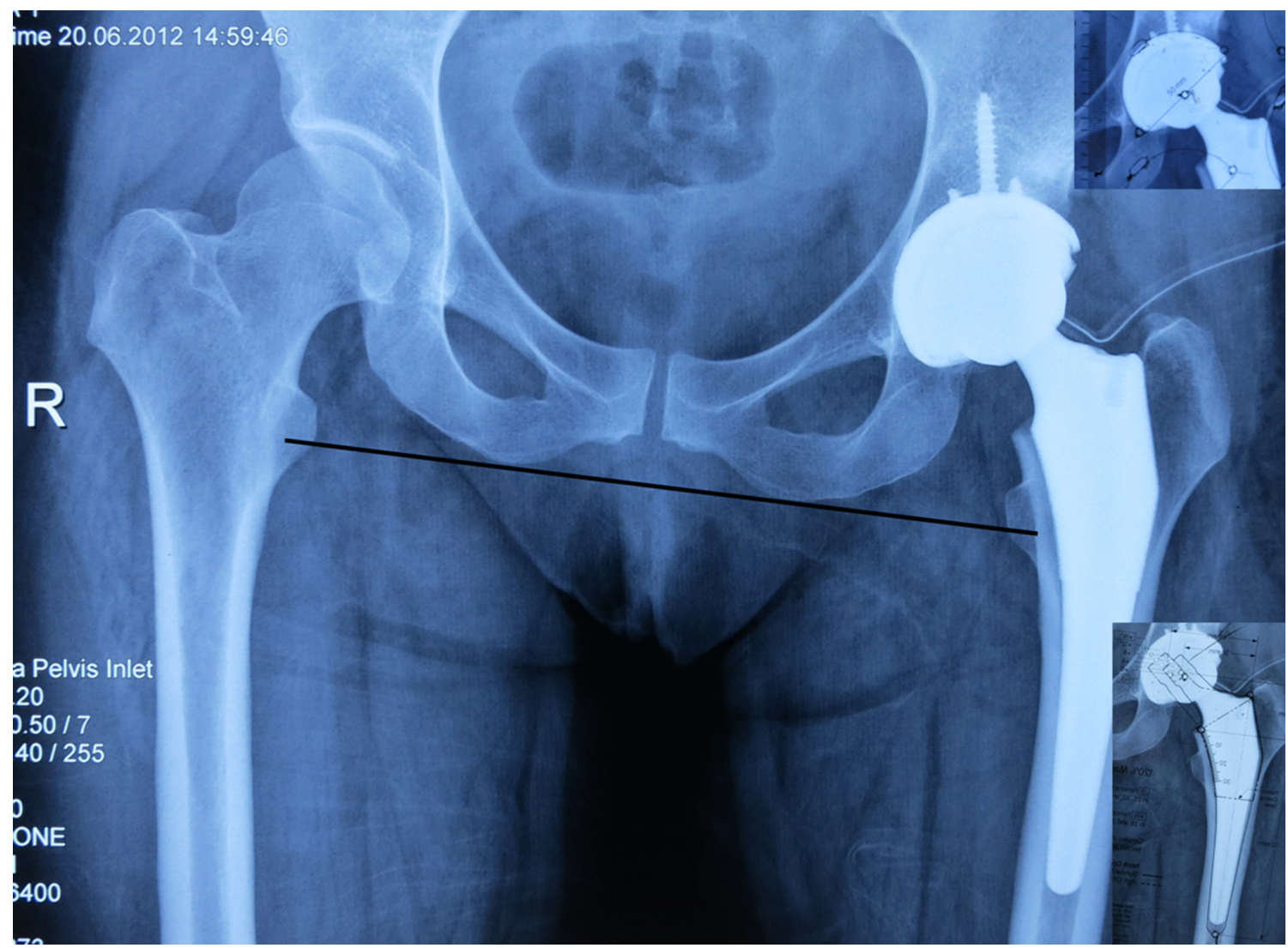

Şekil 3. Ameliyat sonrası görüntü. Ameliyat sonrası uzunluk kontrolü, iskium alt seviyesinden çizilen çizgiye göre eşit trokanter minor seviyeleri.

komponentlerde, çimento mantosu için 2-3 mm boşluk bırakılmalıdır. Asetabuluma yerleştirilen şablonun hareket merkezi ile sağlam kalça hareket merkezinin referans çizgisine olan vertikal uzaklığı ve gözyaşı figürüne olan horizontal uzaklığı karşılaştırılır. Elde edilen farklı değerler bacak uzunluğunu ve ofseti eşitlemek amaçlı femoral şablonlama sırasında telafi edilir.

Romatoid artrit, ankilozan spondilit, Paget Hastalığı veya metabolik hastalıklar ile subkondral kemik zayıflar ve bu nedenle oluşabilecek protruzyo asetabuli durumunda hareket merkezi mediale kayar. Kalça hareket merkezinin lateralizasyonu ve medialde oluşabilecek boşluğun rekonstrüksiyonu amaçlı allogreftin veya çıkarılan femoral başın hazırlanması için gerekli aletler ameliyat öncesi planlamalıdır. Böyle bir durum$\mathrm{da}$, asetabuler komponentin lateralizasyonu gerekli yumuşak doku gerginliği sağlacak ve oluşabilecek femoral sıkışmayı engelleyecektir. Gerçek yerine yerleştirilmiş asetabuler komponent ekstremite boyunu uzatabilir. Ameliyat öncesi, femur boyun kesim seviyesinin bu duruma göre planlanması gerekir. Hipertrofik osteoartritte medial osteofitler asetabulumun lateralize olmasına neden olabilir. Planlamada asetabuler komponent gözyaşı figürüne yaslanmalı ve planlanan oyma işlemine göre şablon yerleştirilerek üst kısmının örtünmesi sağlanmalıdır. Karşılaşılabilecek diğer bir durum ise, asetabulum üst örtünmesinin problem olabileceği kalça displazisi olgularıdır. Displazik kalçada femur, asetabuler yetmezliğine bağlı olarak superolaterale kayabilir. Bu hastalarda, gerçek asetabulum normalden küçük ve yetersiz kemik stoğuna sahip olabileceğinden, ameliyat öncesi hazırlıkların bu doğrultuda yapılması olası sorunları engeller. Asetabulum rekonstrükte edilirken yüksekte kalça merkezi seçeneği kullanılabilir. Gerçek asetabulum seviyesine indirilmesi tercih edilecekse, küçük çaplı (40-42-44 mm) asetabuler komponent ve uygun içlik ve baş seçenekleri hazırlanmalıdır. Ayrıca gerçek asetabulumda tam örtünmeyi sağlamak amacı ile femur kesimi sonrası elde edilen femur başı, asetabulumun superioruna destek amaçlı kullanılabilir. Asetabulum gerçek yerine indirilirken karşılaşılabilecek diğer önemli bir sorun ekstremitenin uzaması sonucu gelişebilecek damar ve sinir problemleri olacaktır. Özellikle $2,5 \mathrm{~cm}$ üzerinde bir uzama, olası riski arttıracağından femoral osteotomi gerektirebilir. ${ }^{[21]}$ 


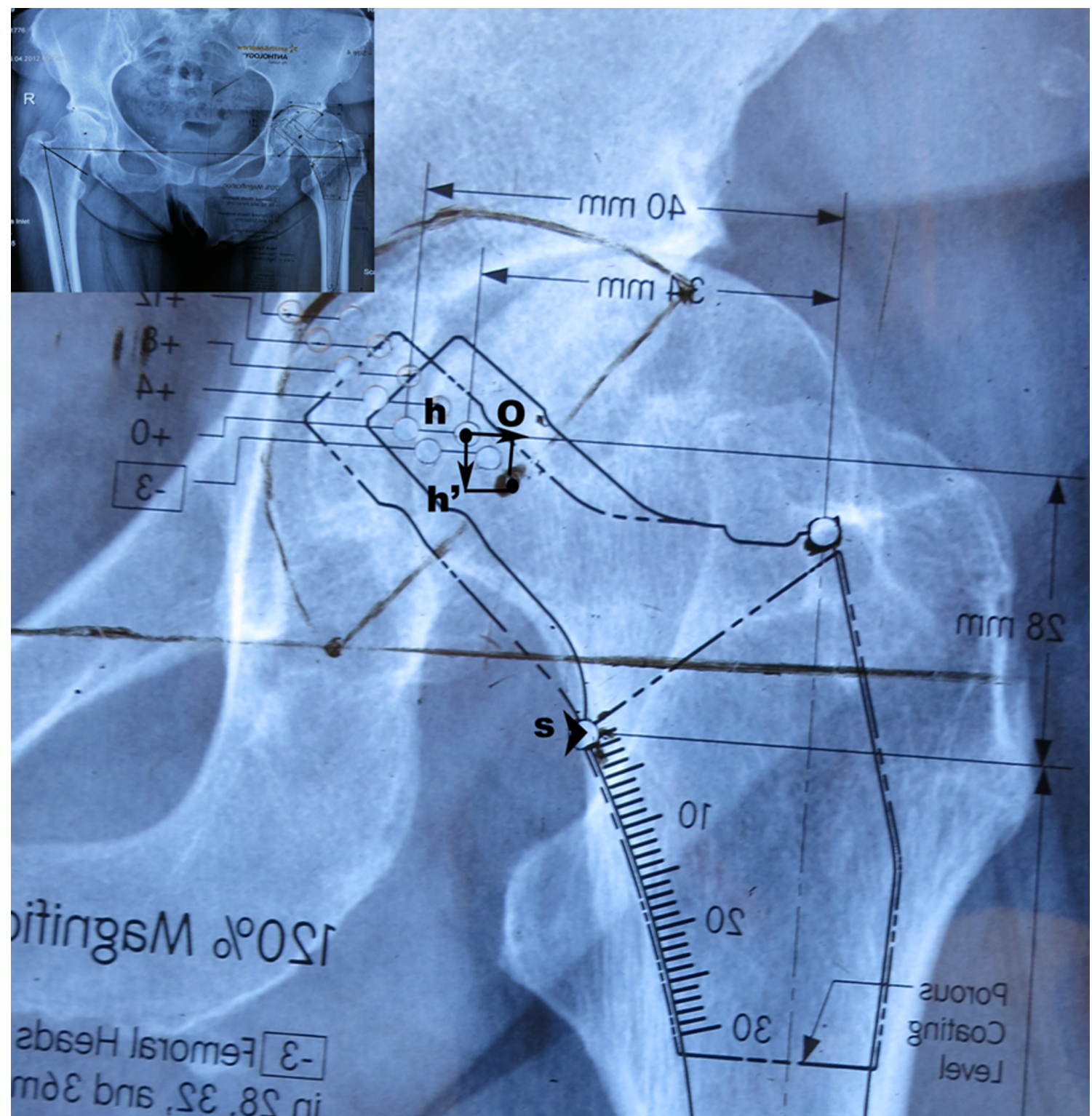

Şekil 4. Planlanan uzama miktarı. Ekternal rotasyonda bulunan ekstremitede diğer femura göre belirlenen osteotomi seviyesi (S) ve femoral komponentin yerleştirilmesi ile beraber oluşacak uzama (h-h') ve lateralizasyon miktarı [h-O].

Asetabuler komponent şablonu ile yeni kalça hareket merkezi belirlendikten sonra femoral şablonlamaya geçilir. Şablon ile yapılacak olan planlama, kullanılacak komponent tasarımına göre farklılık gösterir. Proksimal kaplı çimentosuz femoral komponent için femur proksimal kısmı doldurulurken tümü kaplamalı femoral komponent için şablon femur diafizine oturtulur. Bu tip komponentlerin birincil stabilitesi için gövdenin, endosteal duvar ile medial ve lateralden birkaç santimetrelik teması önerilir (Şekil 2, 3). ${ }^{[22]}$ Çimentolu protezler için ise 2-3 mm'lik çimento mantosu payı bırakılmalıdır.
Ameliyat öncesi planlamada uzunluk farkı, trokanter minorun proksimal kenarı ile gözyaşı figürleri arası referans çizgisine olan vertikal mesafe ile ölçülür. Ameliyat sonrası elde edilecek uzunluk farkı asetabulum hareket merkezi ile femurun hareket merkezi arasındaki fark kadar olacaktır (Şekil 4).

Femoral ofset normal eklem ofseti kadar ayarlanmalıdır. Femoral komponentin hareket merkezi asetabulum merkezi medialinde kalırsa rekonstrüksiyon sonrasında ofset artar (Şekil 4). Eğer femur hareket merkezi asetabuler merkezin lateralinde kalırsa ofset azalır ve 


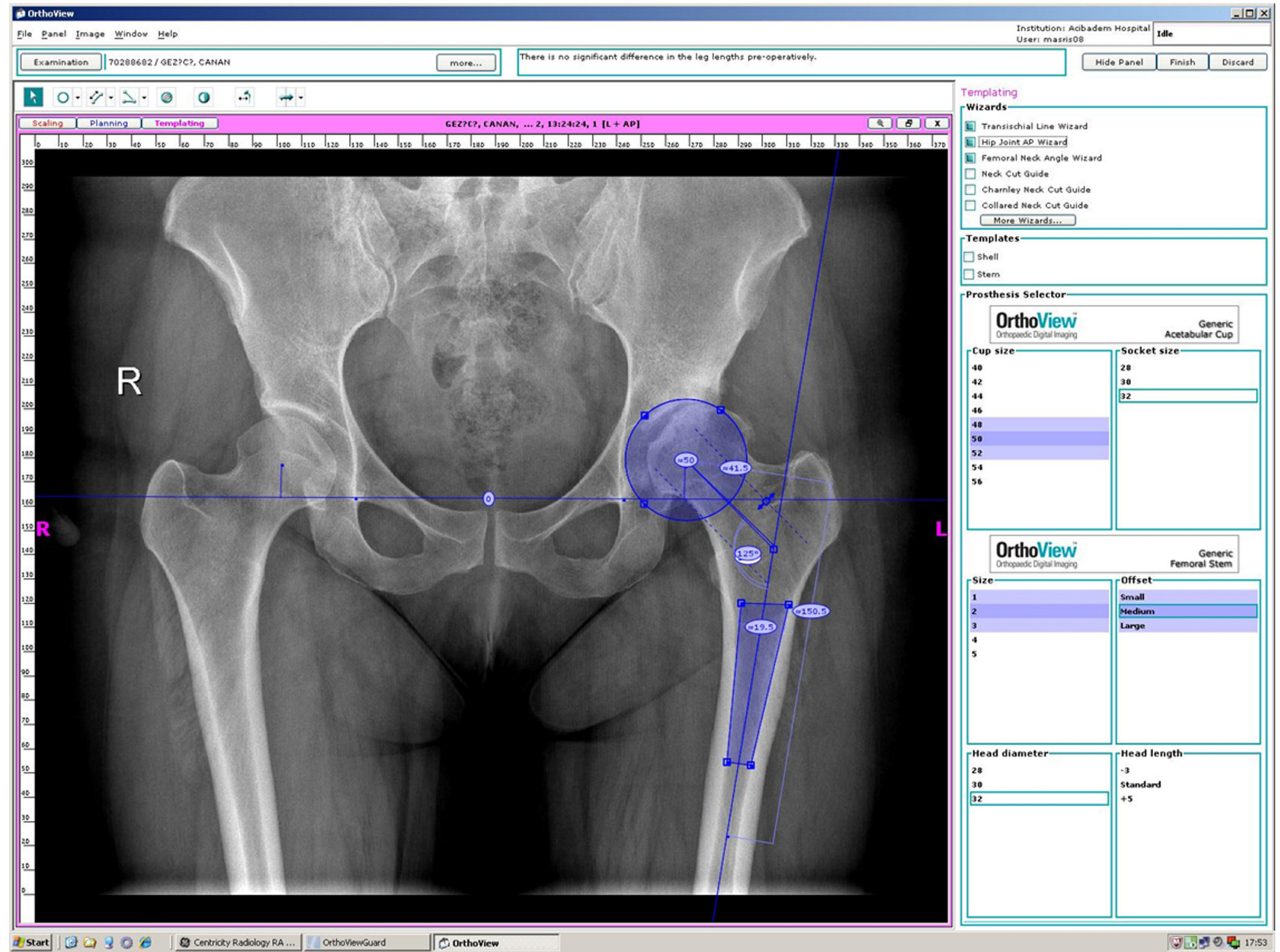

Şekil 5. Ameliyat öncesi dijital ortamda ölçüm.

böyle bir durumda yüksek ofsetli femoral komponent seçeneği kullanılması gerekebilir. íleri artroz ile beraber gelişen eksternal rotasyon deformitesi, şablonlamada ofsetin yanlış değerlendirilmesine neden olur. Bu durumda normal kalça üzerinden planlama yapılması gerekir. Her iki tarafta ileri artroz bulunuyorsa ameliyat sırasında femur disloke edilip kesim öncesinde trokanter majör ile femur başı hareket merkezi arasındaki yatay mesafe (ofset) tespit edilir. Femoral komponentin pozisyonu ve ofseti belirlendikten sonra femura yapılacak osteotominin seviyesi ve açısı işaretlenir. Trokanter minörun üst kısmından kalça hareket merkezine olan dikey mesafe ve femur boyun osteotomisine olan mesafeler ölçülür. Çimentolu protez kullanılacak ise distal ortalayıcı çapı, tıkacın büyüklüğü ve yerleştirilecek derinlik şablonlama ile belirlenir.

Dijital radyografinin yaygın olarak kullanılması ve büyütme faktörünün hesaplamalardaki yanıltıcı etkileri, planlamanın özel yazılımlar vasıtası ile bilgisayar ekranı üzerinden yapılmasını gerektirmiştir (Şekil 5).
Dijital olarak yapılan ölçümlerin, asetat ile film üzerinden yapılan ölçümler kadar güvenilir olduğu gösterilmiştir. ${ }^{[23]}$ Hatta film üzerinden ölçümlere göre daha kesin sonuç verdiğini ve klasik şablonlamadan üstün olduğunu gösteren çalışmalar mevcuttur. ${ }^{[24]}$

Ameliyat öncesi planlama ile cerrahide yüksek olasılıkla başarı sağlansa bile, cerrahi sırasındaki senaryo planlamadan farklı olabilir. Asetabuler komponentin planlanandan büyük yerleştirilmesi hareket merkezinin distale yer değiştirmesine veya planlanandan daha büyük femoral komponentin uygulanması boyun uzunluğu ve offsetin artmasına neden olur. Özellikle femoral komponent uygulaması sırasında, sadece ameliyat öncesi planlamaya güvenilmemelidir. Femoral kanalın hazırlığı aşamasında raspalama ve deneme sırasında kemiğin dikkatli gözlenmesi olası kırık ve komplikasyon riskini azaltır. Ameliyat öncesi planlama, cerrahi teknik ve implant seçimi açısından bir çerçeve çizer. Ancak implant tipi ve boyutları ile ilgili kesin karar ameliyat sırasında ortaya çıkan tabloya bağlı olarak verilir. 


\section{KAYNAKLAR}

1. Kim, YH. Total arthroplasty of the hip after childhood sepsis. J Bone Joint Surg Br 1991;73(5):783-6.

2. Jupiter JB, Karchmer AW, Lowell JD, Harris WH. Total hip arthroplasty in the treatment of adult hips with current or quiescent sepsis. J Bone Joint Surg Am 1981;63(2):194-200.

3. Chandler HP, Penenberg BL. Bone Stock Deficiency. In: Total Hip Replacement: Classification and Management. Thorofare, NJ: Slack; 1989. p. 41-6.

4. Binns $M$, Pho R. Femoral vein occlusion during hip arthroplasty. Clin Orthop Relat Res 1990;(255):168-72.

5. Cameron HU. Hip surgery in aortofemoral bypass patient. Orthop Rev 1988;17(2):195-7.

6. Aufranc OE, Aufranc ST. Evaluation of the patient with an arthritic hip. In: Stillwell WT, editor. The Art of Total Hip Arthroplasty. Orlando, FL: Grune \& Stratton; 1987. p. 123-32.

7. Beattie P, Isaacson K, Riddle DL, Rothstein, JM. Validity of derived measurements of leg-length differences obtained by use of a tape measure. Phys Ther 1990;70(3):150-7.

8. Della Valle AG, Padgett DE, Salvati EA. Preoperative planning for primary total hip arthroplasty. J Am Acad Orthop Surg 2005;13(7):455-62.

9. Aaron A, Weinstein D, Thickman D, Eilert R. Comparison of orthoroentgenography and computed tomography in the measurement of limb-length discrepancy. J Bone Joint Surg Am 1992;74(6):897-902.

10. Buly RL, Huo M, Root L, Binzer T, Wilson PD Jr. Total hip arthroplasty in cerebral palsy. Long-term follow-up results. Clin Orthop Relat Res 1993;(296):148-53.

11. Bischoff R, Dunlap J, Carpenter L, DeMouy E, Barrack R. Heterotopic ossification following uncemented total hip arthroplasty. Effect of the operative approach. J Arthroplasty 1994;9(6):641-4.

12. Massin P, Duparc J. Total hip replacement in irradiated hips. A retrospective study of 71 cases. J Bone Joint Surg Br 1995;77(6):847-52.

13. Guyen O, Pibarot V, Vaz G, Chevillotte C, Carret JP, BejuiHugues J. Unconstrained tripolar implants for primary total hip arthroplasty in patients at risk for dislocation. J Arthroplasty 2007;22(6):849-58.
14. Barack RL, Stephen R, Burnett J. Preoperative Planning.In: Callaghan JJ, Rosenberg AG, Rubash HE, editors. The Adult Hip, 2nd ed. USA: Lippincott Williams \& Wilkins; 2007. p. 884-910.

15. D'Antonio JA. Preoperative templating and choosing the implant for primary THA in the young patient. Instr Course Lect 1994;43:339-46.

16. Crawford RW, Psychoyios V, Gie G, Ling R, Murray D. Incomplete cement mantles in the sagittal femoral plane: an anatomical explanation. Acta Orthop Scand 1999;70(6):596-8.

17. Dorr LD, Faugere MC, Mackel AM, Gruen TA, Bognar B, Malluche $\mathrm{HH}$. Structural and cellular assessment of bone quality of proximal femur. Bone 1993;14(3):231-42.

18. Carter LW, Stovall DO, Young TR. Determination of accuracy of preoperative templating of noncemented femoral prostheses. J Arthroplasty 1995;10(4):507-13.

19. Massin P, Schmidt L, Engh CA. Evaluation of cementless acetabular component migration. An experimental study. J Arthroplasty 1989;4(3):245-51.

20. Goodman SB, Adler SJ, Fyhrie DP, Schurman DJ. The acetabular teardrop and its relevance to acetabular migration. Clin Orthop Relat Res 1988;(236):199-204.

21. Harris WH. Hamptom BJ. Total Hip Arthroplasty. The Management of Arthritis Secondary to Developmental Dysplasia of the Hip. In: Callaghan JJ, Rosenberg AG, Rubash HE, editors. The Adult Hip, 2nd ed. USA: Lippincott Williams \&Wilkins; 2007. p. 1127-41.

22. Engh CA, Bobyn JD. Biological Fixation in Total Hip Arthroplasty. NJ: Slack; 1985.

23. Iorio R, Siegel J, Specht LM, Tilzey JF, Hartman A, Healy WL. A comparison of acetate vs digital templating for preoperative planning of total hip arthroplasty: is digital templating accurate and safe? J Arthroplasty 2009;24(2):175-9. CrossRef

24. Gamble P, de Beer J, Petruccelli D, Winemaker M. The accuracy of digital templating in uncemented total hip arthroplasty. J Arthroplasty 2010;25(4):529-32. CrossRef 